\title{
Robotic resource exploration is a key to human expansion through the cosmos
}

Jeffrey S. Kargel, Wolfgang Fink, Roberto Furfaro, Hideaki Miyamoto

Jeffrey S. Kargel, Wolfgang Fink, Roberto Furfaro, Hideaki Miyamoto, "Robotic resource exploration is a key to human expansion through the cosmos," Proc. SPIE 6960, Space Exploration Technologies, 69600F (15 April 2008); doi: 10.1117/12.784643

SPIE Event: SPIE Defense and Security Symposium, 2008, Orlando, Florida, United States 


\title{
Robotic Resource Exploration is a Key to Human Expansion Through the Cosmos
}

\author{
Jeffrey S. Karge $\mathrm{l}^{\mathrm{a}}$, Wolfgang Fink ${ }^{\mathrm{b}}$, Roberto Furfaro ${ }^{\mathrm{c}}$, Hideaki Miyamoto ${ }^{\mathrm{d}}$, \\ ${ }^{a}$ Department of Hydrology \& Water Resources, University of Arizona, Tucson, AZ, USA 85721 \\ ${ }^{\mathrm{b}}$ California Institute of Technology, Visual and Autonomous Exploration Systems Research \\ Laboratory, Division of Physics, Mathematics \& Astronomy, Pasadena, CA, USA \\ ${ }^{c}$ Department of Aerospace \& Mechanical Engineering, University of Arizona, Tucson, AZ, USA \\ ${ }^{\mathrm{d}}$ Hideaki Miyamoto, University Museum, University of Tokyo, Japan
}

\begin{abstract}
If the goal of planetary exploration is to build a permanent and expanding, self-sustaining extraterrestrial civilization, then clever and myriad uses must be made of planetary resources. Resources must be identified and evaluated according to their practicality. A new economy should be devised based on resource occurrence, ore accessibility, options for ore transport, material beneficiation, and manufacturing; end uses and demand; and full economic cost/benefit assessment. Locating and evaluating these resources should be done with coordinated robotic assets arrayed in orbit and on the surface. Sensor arrays and tandem on-ground means of physical manipulation of rocks should incorporate highly capable onboard data processing, feature detection, and quantification of material properties; intelligent decision making; a flexible capacity to re-order priorities and act on those priorities in carrying out exploration programs; and human-robot interaction. As resource exploration moves into exploitation, sensors working in tandem with robust physical manipulation will place increased emphasis on automation in effective and safe robotic quarrying, tunneling, boring, and ore beneficiation. Any new global planetary economy will have to weigh the efficiency of resource identification and utilization with full-spectrum cost/benefit assessment for human health and safety, the environment, future habitability and sustainability, and human priorities in the development and growth of civilization. It makes no sense to rove from one planet to another in a wave of resource use and depletion, like interplanetary locusts. Robotic systems will open new worlds to human use, but they will also place a premium on human ability to control exponentially growing consumption.
\end{abstract}

Keywords: Moon, Mars, asteroid, space resources, in situ resource utilization, robotics, space exploration

\section{INTRODUCTION}

Human space exploration is projected to expand to long-term or permanent habitation of the Moon, Mars, and elsewhere. If the goal of human planetary exploration is to go somewhere and return to Earth, e.g., Apollo-style forays to the Moon or Mars, then limited exploration for and use of local planetary resources (e.g., for rocket propellant manufacturing) may aid an "Apollo Plus" program. At this time in history, such a closed-ended engineering effort, capped by an end date, seems to miss the human spirit.

If our goal is to build a permanent, expanding, self-sustaining extraterrestrial civilization, then clever and myriad uses must be made of global planetary resources. First, resources of asteroids, the Moon, and Mars should be identified (Lewis et al. 1993, Baker et al. 1993, Kargel 1994, 1996, 1997, 2004). A new Solar System economy should be based on resource occurrence and accessibility, options for ore transport and material beneficiation, manufacturing and other technological uses, and economic cost and benefit. Locating and evaluating resources should be done with coordinated robotic flyby, orbital, and surface assets (Fink et al. 2005, 2006a, 2007). Sensor arrays and tandem onground physical manipulation of rocks must incorporate advanced onboard data processing, feature detection, and quantification of material properties; intelligent decision making; flexible capacity to re-order exploration priorities; and human-robot interaction (Fink et al. 2008, 2006b). A scheme based on fuzzy autonomous cognition and decision

* e-mail: jkargel1054@earthlink.net; phone: +1-520-579-3194 , mobile: +1-520-780-7759

Space Exploration Technologies, edited by Wolfgang Fink

Proc. of SPIE Vol. 6960, 69600F, (2008) · 0277-786X/08/\$18 · doi: 10.1117/12.784643

Proc. of SPIE Vol. $696069600 \mathrm{~F}-1$ 
has been proposed for astrobiological exploration (Furfaro et al. 2008) and should be developed for resource exploration, too.

As resource exploration moves to exploitation, robotic sensors working in tandem with robust physical manipulation will place increased emphasis on automation in effective quarrying, tunneling, boring, and ore beneficiation. Terrestrial mining is entering undersea and mid-crustal levels of Earth, and similar robotic approaches are being developed. Planetary resource exploration and exploitation will place more emphasis than ever on intelligent robotic systems. A new global planetary economy will have to weigh the efficiency of resource identification and utilization with full-spectrum cost/benefit assessment for human health and safety, the environment, future habitability and sustainability, and human priorities in the development and growth of civilization.

\section{A CALL FOR SOLAR SYSTEM RESOURCE EXPLORATION AND MAPPING}

Asteroids are rightly perceived by many as the vital stepping stones to the stars. Asteroids will provide the raw material for rocket propulsion and space construction more readily than can lunar resources (Lewis 1993, 1997). Asteroids also can provide riches for Earth, including vastly increased supplies of platinum metals (Kargel 1994), and materials for construction in low Earth orbit of space solar power stations and orbiting factories and habitats (O'Neill 1976, Kargel 1997, Glaser et al. 1998). The Moon, however, has the current political favor, and it, too, can potentially serve as a useful source of some of these materials.

Although the long-range destiny of humanity may well be the stars, probably the most exciting practical destination for settlement within the Solar system is Mars. Mars may have too large a gravity well to serve effectively as a stepping stone to the stars, but as a world of natural resources, it has what is needed to make for a humanly habitable world (Zubrin and Wagner 1996, Kargel 2004). As Zubrin is fond of saying, "The Moon is a Rock. Mars is a Planet." The geology and geochemistry of the Moon, Mars, and asteroids, particularly the diversity of potential resources related to planetary geological history and complexity, would seem to bear out what Zubrin says to some degree. Mars is a water rich world, and there is no substitute for water as an agent of chemical transformation and transport of planetary materials.
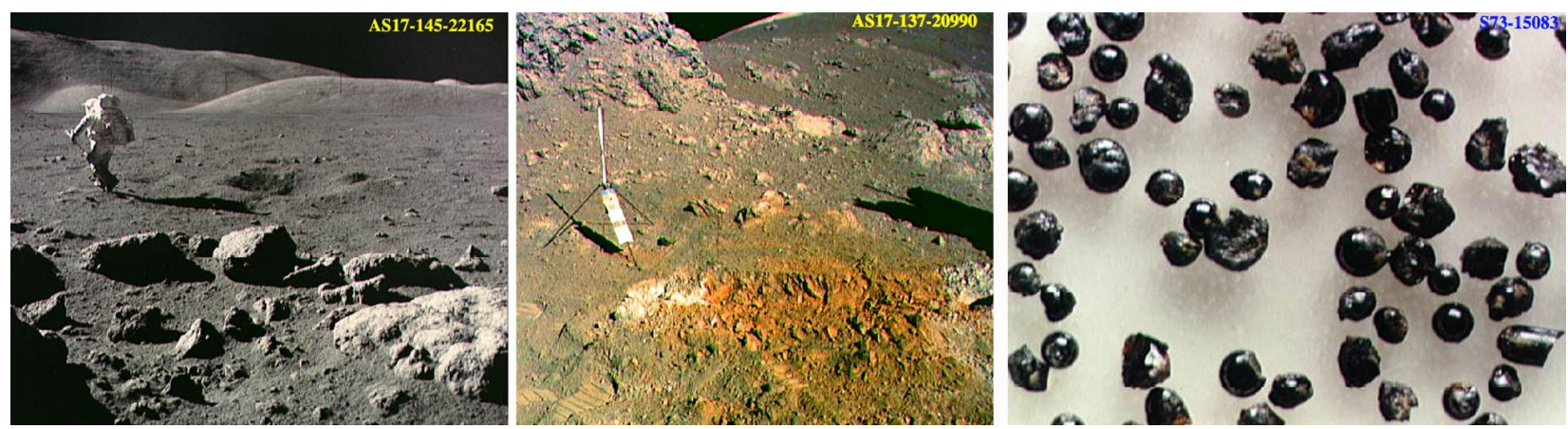

Fig. 1. Apollo 17 astronaut Harrison "Jack" Schmitt (panel on the left) explored the lunar surface in December 1972 with Eugene Cernan. Serendipitously, they discovered orange soil (slightly color-enhanced in middle panel), which turned out to be helium-3-impregnated titanium oxide-rich volcanic glass (Schmitt 1990). The glass spherules (150-200 $\mu \mathrm{m}$ diameter, right panel) originally were emplaced by explosive volcanism following the giant impact that formed the nearby Serenitatis Basin. The titanium oxide-rich soil is a possible source of oxygen to sustain a human presence and to fuel rockets in low Earth orbit; the helium-3 extracted from such materials could be imported to Earth and power fusion power generating plants of the future. Whereas helium-3 occurs as a trace isotope in all lunar soils, it turns out that the Apollo 17 site has what may be the highest abundance of the gas anywhere on the Moon due to the particular titanium-rich chemical nature of the local soil, the age of the soil, and the fluence of solar wind (which supplies the helium-3) at that site.

The Moon, however, is more geologically diverse than sound bites would suggest. The Moon has a complex igneous history, which has generated materials as diverse as KREEP basalts (a possible rich resource of volatile-rich 
materials, containing phosphorous and other minerals, even ore-grade quantities of rare earth elements and uranium) and the titanium-rich orange volcanic soils discovered serendipitously by geologist-astronaut Jack Schmitt in 1972 (Fig. 1). There are unique and valuable attributes of the Moon's history and environment, such as the fact that it is a solar wind and helium-3 sponge that has no parallel on Mars and probably not on asteroids, either, due to (a) the lack on asteroids of materials comparable to the helium-adsorbing titaniferous volcanic glass on the Moon; (b) the lack of stability and surface exposure of soils on asteroids and Mars for billions of years; and (c) the inability of solar wind to penetrate through the Martian atmosphere. If ${ }^{3} \mathrm{He}$-based fusion energy ever is made practical, the Moon will be the fuel source.

Planetary core formation has rendered certain elements basically inaccessible on the Moon and Mars, as it has on Earth, but these processes and fractional crystallization of the cores have produced incredible riches of these same elements on some asteroids (Kargel 1994, 1996, 1997). Platinum-group metals, gold, gallium and germanium, and some other precious metals are enriched thousands or even tens of thousands of times in some metallic asteroid bodies (as assessed from meteorite compositions) compared what they are in the average continental crust of Earth, and tens of times what they are in gold and platinum ore bodies on Earth. Potentially these precious metals could be imported to Earth and revolutionize industry here as many applications now impossible (or not even yet imagined) due to the lack of supply and high market prices suddenly become possible at collapsed market prices and orders of magnitude increased supply of some of these metals. As Kargel (1994) modeled, the price elasticity in an era of asteroid mining is calculable, and even at collapsed prices hundreds of billions of dollars' worth of these metals could be produced in periods of about 2 decades; and that may be just the beginning. One of the issues that seemed most problematic to Kargel in his 1990 's work on asteroid mining - the disaggregation of asteroidal material into manageable mass increments - turns out to have been settled naturally for some asteroids; Hayabusa spacecraft images have shown the minuscule near-Earth asteroid Itokawa to be a veritable rubble pile ready for manipulation and ore processing (Fig. 2, Miyamoto et al., 2007). However, as judged by meteorites, asteroids are chemically and mineralogically extremely diverse and heterogeneous; before exploitation must come a comprehensive survey of near-Earth asteroids and eventually main belt asteroids.

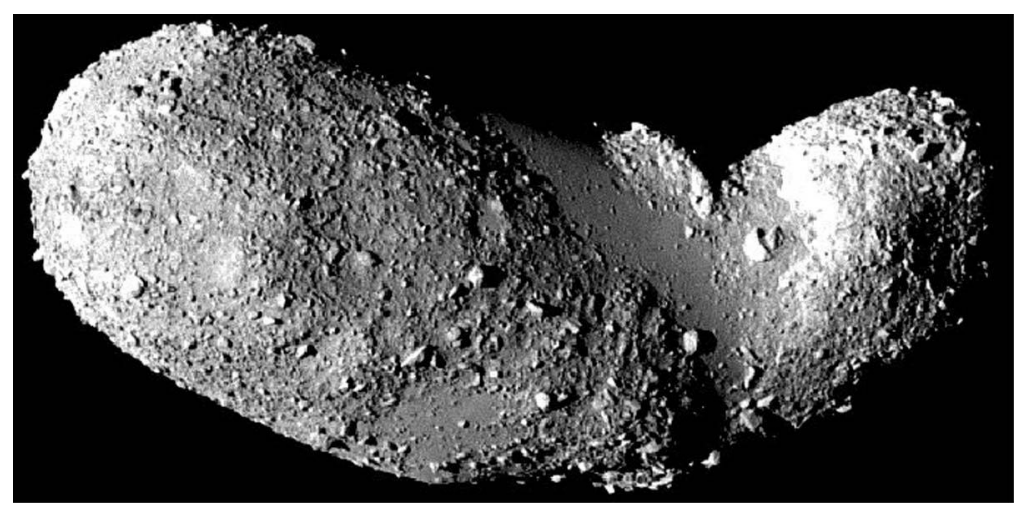

Fig. 2. Hayabusa spacecraft image of asteroid Itokawa revealed it to be a rubble pile, albeit one with intriguing regolith sorting processes (Miyamoto et al. 2007). The asteroid, about $300 \mathrm{~m}$ long, had not been expected to possess such a regolith, but the fact that it does would aid any effort to derive mineral wealth from such an object.

It is thus the collection of diverse worlds spanning the inner Solar System that we expect will end up making the case for an integrated Solar System economy. First, we need to know exactly what is out there, and how the materials can be accessed and folded into a Solar System economy.

A coordinated and comprehensive program of resource exploration in near-Earth space (Moon, Mars, and asteroids) is needed (Lewis 1993). This can be assisted by astronaut activities, but a cost effective thorough approach necessitates automation and use of intelligent robots. Multi-object flybys for resource reconnaissance among the asteroids, orbiters, landers, and subsurface explorers are needed in a hierarchical program (Fink et al. 2005, 2006a, 2007). National space agencies should coordinate plans, share technologies for automation, and agree to release and jointly analyze planetary data on a timely basis. 


\section{THE EXAMPLE PRESENTED BY MARTIAN MINERAL RESOURCES}

If we go to Mars, we should go to stay. That will require development of a full Mars economy. A Mars economy will require development of an industrial base and infrastructure rooted in use of raw materials mainly from Mars. That planet is far better suited to industrial development of a self-sustaining civilization than is the Moon. $\mathrm{H}_{2} \mathrm{O}$ and $\mathrm{CO}_{2}$ are what have made most of the crucial differences - myriad differences. Hydrolysis has broken bonds in silicate lattices, reconstituted ionic materials, and made them available. Kargel (2004) described how the basic materials from which a civilization can be built can be manufactured from abundant materials available on the surface of Mars. For example, soluble phosphate, sulfate, and ammonium fertilizers can be manufactured readily from sulfate salts, such as present in abundance at Meridiani Planum (Fig. 3), from Martian atmospheric nitrogen, natural phosphate minerals and hydrogen gas produced from water vapor, ice, or hydrated salts. A full-spectrum petrochemical base, including the polymers used in our civilization on Earth for clothing, appliances, and building materials, can be manufactured on Mars using primarily air and hydrogen generated from ice or hydrated salts. Ceramics, glasses, Portland cement and concrete; adobe; steel; and other construction materials all can be produced from materials readily available on Mars.

Some environmental conditions, such as low ambient temperatures and low relative humidity, will require different formulations of some materials and allow use of some substances that would not work on Earth; for example, at higher latitudes, ice could be moulded or stacked in bricks or blocks to make roadways, foundations, and building structures, so long as it was not intended to heat those buildings; at lower latitudes, ice would not remain stable unless physically isolated against sublimation, but chloride and sulfate salts - readily available in some rock depositscould be dissolved and then precipitated with sand or stone aggregate to make ice-free hydrate-bonded concrete without going through the energy-intensive steps of making lime or Portland cement.

To give some solidity to our claims that the building materials of civilization can be manufactured from indigenous Martian resources, let us consider briefly how fertilizers could be manufactured from materials we know are there.

$\mathrm{CaSO}_{4}$ or $\mathrm{MgSO}_{4}$ are known to be widespread across parts of Mars and are abundant components of soil and occur in freeze-dried lake beds on Mars and freeze-dried brine-impregnated sand dunes, such as those at the Meridiani Planum site explored by NASA's Opportunity rover (Squyres et al. 2004). The water of hydration of the chief $\mathrm{Ca}$ and $\mathrm{Mg}$ sulfates first would be driven off by heating and claimed for use in other processes:

$$
\begin{aligned}
& \mathrm{CaSO}_{4} \cdot 2 \mathrm{H}_{2} \mathrm{O} \text { (gypsum) } \rightarrow \mathrm{CaSO}_{4}(\text { anhydrite })+2 \mathrm{H}_{2} \mathrm{O}(\mathrm{l}) . \\
& \mathrm{MgSO}_{4} \cdot \mathrm{xH}_{2} \mathrm{O} \rightarrow \mathrm{MgSO}_{4}(\mathrm{~s})+2 \mathrm{H}_{2} \mathrm{O}(\mathrm{l}),
\end{aligned}
$$

where several hydration states of magnesium sulfate result in, for a few examples, $x=1$ kieserite, $x=6$ hexahydrite, $x$ $=7$ epsomite. Next, sulfur dioxide gas or liquid sulfur dioxide would be generated by further heating:

$$
\begin{aligned}
& \mathrm{CaSO}_{4}(\mathrm{~s}) \rightarrow \mathrm{CaO}(\mathrm{s})+\mathrm{SO}_{2}(\mathrm{~g})+1 / 2 \mathrm{O}_{2}(\mathrm{~g}) . \\
& \mathrm{MgSO}_{4}(\mathrm{~s}) \rightarrow \mathrm{MgO}(\mathrm{s})+\mathrm{SO}_{2}(\mathrm{~g})+1 / 2 \mathrm{O}_{2}(\mathrm{~g}) .
\end{aligned}
$$

Alternatively, elemental sulfur from volcanic fumarole deposits or sulfide minerals such as pyrite could provide the sulfur needed for sulfur dioxide generation.

After $\mathrm{SO}_{2}$ is produced, it is oxidized at high temperature with a metallic catalyst, such as sponge metal (vanadium or platinum-palladium), to form $\mathrm{SO}_{3}$ gas, with the oxygen having been made available from reactions 3 or 4 :

$$
\mathrm{SO}_{2}(\mathrm{~g})+1 / 2 \mathrm{O}_{2}(\mathrm{~g}) \rightarrow \mathrm{SO}_{3}(\mathrm{~g})
$$

$\mathrm{SO}_{3}$ then spontaneously combines with water to form sulfuric acid, either a solution when excess water is available or pure liquid sulfuric acid:

$$
\mathrm{SO}_{3}(\mathrm{~g})+\mathrm{H}_{2} \mathrm{O}(\mathrm{l}) \rightarrow \mathrm{H}_{2} \mathrm{SO}_{4}(\mathrm{l})
$$

Then ammonia is produced by reacting hydrogen gas with nitrogen at high temperature, commonly with a metallic catalyst:

$$
3 \mathrm{H}_{2}(\mathrm{~g})+\mathrm{N}_{2}(\mathrm{~g}) \rightarrow 2 \mathrm{NH}_{3}(\mathrm{~g}) .
$$


The Martian atmosphere contains about 4-5\% nitrogen, which is the main residual gas after carbon dioxide is frozen out. Oxygen also has to be removed, whereas atmospheric argon gas can remain without disturbing reaction 7 . The hydrogen can be produced from water, which may be derived from ice or by driving off the water of hydration of salts.

Once we have ammonia and sulfuric acid, the first of our needed soluble fertilizers is easily produced:

$$
2 \mathrm{NH}_{3}(\mathrm{aq})+\mathrm{H}_{2} \mathrm{SO}_{4}(\mathrm{aq}) \rightarrow\left(\mathrm{NH}_{4}\right)_{2} \mathrm{SO}_{4}(\mathrm{aq})
$$

Ammonium sulfate can be manufactured by an alternative process that uses ammonia from reaction 7 and $\mathrm{CO}_{2}$ derived from the atmosphere and excess water produced from ice or hydration water:

$$
\begin{aligned}
& 2 \mathrm{NH}_{3}(\mathrm{aq})+\mathrm{CO}_{2}(\mathrm{aq})+\mathrm{H}_{2} \mathrm{O}(\mathrm{l}) \rightarrow\left(\mathrm{NH}_{4}\right)_{2} \mathrm{CO}_{3}(\mathrm{aq}) \\
& \left(\mathrm{NH}_{4}\right)_{2} \mathrm{CO}_{3}(\mathrm{aq})+\mathrm{CaSO}_{4}(\mathrm{aq}) \rightarrow\left(\mathrm{NH}_{4}\right)_{2} \mathrm{SO}_{4}(\mathrm{aq})+\mathrm{CaCO}_{3}(\mathrm{~s})
\end{aligned}
$$

Soluble phosphates can be manufactured using natural fluorapatite feedstocks mined from pegmatite rocks or silicic hydrothermal veins. Water-soluble calcium dihydrogen phosphate can be manufactured by reacting the natural phosphate mineral with sulfuric acid from reaction 6:

$$
2 \mathrm{Ca}_{5}\left(\mathrm{PO}_{4}\right)_{3} \mathrm{~F}(\mathrm{~s})+7 \mathrm{H}_{2} \mathrm{SO}_{4}(\mathrm{aq}) \rightarrow 3 \mathrm{Ca}\left(\mathrm{H}_{2} \mathrm{PO}_{4}\right)_{2}(\mathrm{aq})+7 \mathrm{CaSO}_{4}(\mathrm{aq})+2 \mathrm{HF}(\mathrm{g})
$$

The calcium sulfate also produced can be further used in reactions 3 or 10 to make more fertilizers, and the hydrofluoric acid would find many other uses elsewhere in the chemical industry.

Urea, an animal feed supplement and an important fertilizer, can be produced by:

$$
2 \mathrm{NH}_{3}(\mathrm{~g})+\mathrm{CO}_{2}(\mathrm{~g}) \rightarrow\left(\mathrm{NH}_{2}\right)_{2} \mathrm{CO}(\mathrm{aq})+\mathrm{H}_{2} \mathrm{O}(\mathrm{l})
$$

Thus, all the major fertilizers can be manufactured using Martian resources.

Though an industrial Mars city will not look like a terrestrial city and its economy will not be structured similarly, there is little we can think of in Earth's cities that could not be replicated or improved upon on Mars. With road building materials readily available on Mars, cars could be manufactured there, too. Liquid fuels and oxidizers for automobiles, oxygen for the artificial environment in the car, rubber polymers for the car tires and driving gloves, glass for the car's pressurized enclosed habitat, and everything right down to whiskey and dance floors at the other end of the road, can all be stamped "Made on Mars." Of course, we would not seek to emulate on Mars the lack of sustainability permeating Earth's current dead-end economy and civilization. It will, however, require utilization of Martian rock deposits. Mining and mining engineering will be front and center as we settle onto Mars.

An important part of the early Mars chemical industry will involve production of hydrocarbons from inorganic carbon dioxide. Polymers are needed on Mars for the many reasons they are utilized on Earth for manufacture of construction materials, textiles, and so on. A key initial step is the production of carbon monoxide by heating atmospheric carbon dioxide, or by oxidizing elemental carbon (such as graphite). The reverse water gas shift reaction, for instance, has been examined by Zubrin et al. (1997):

$$
\mathrm{CO}_{2}+\mathrm{H}_{2} \rightarrow \mathrm{CO}+\mathrm{H}_{2} \mathrm{O}
$$

This reaction is somewhat endothermic, so it requires energy input, and it is inefficient with its yield of carbon monoxide. However, this reaction has been proposed as a means of formation of water and, via electrolysis, oxygen, if other sources of water are not easily available (Zubrin et al. 1997). As a source of carbon monoxide, the reaction has less to offer than graphite oxidation, if a mineral supply of graphite can be found. The reverse water gas shift reaction can be run with other parallel systems to produce methanol or ethylene (Zubrin et al. 1997), which can be utilized as rocket propellants or elsewhere in the chemical industry.

Fischer-Tropsch processes then produce hydrocarbons by carefully controlled reactions of the carbon monoxide with hydrogen, which can be generated from ice or water of hydration of minerals. Fischer-Tropsch processes involve the catalytic hydrogenation of carbon monoxide in the presence of a heated catalyst of iron, cobalt, or other metals or carbon nitride; reactions proceed efficiently at temperatures of $470-600 \mathrm{~K}$ and pressures from $100 \mathrm{kPa}$ to $20 \mathrm{MPa}$, 
Alcohols, paraffins, and straight-chain alkenes (olefins) are typically produced this way in Earth's petrochemical industry. Gas-phase reactions include:

Alkane production: $\quad(\mathrm{n}+1) \mathrm{H}_{2}+2 \mathrm{nCO} \rightarrow \mathrm{C}_{\mathrm{n}} \mathrm{H}_{2 \mathrm{n}+2}+\mathrm{nCO}_{2} \quad$ (iron catalyzed)

Alkane production: $\quad(2 \mathrm{n}+1) \mathrm{H}_{2}+\mathrm{nCO} \rightarrow \mathrm{C}_{\mathrm{n}} \mathrm{H}_{2 \mathrm{n}+2}+\mathrm{nH}_{2} \mathrm{O} \quad$ (cobalt catalyzed)

Alkene production: $2 \mathrm{nH}_{2}+\mathrm{nCO} \rightarrow \mathrm{C}_{\mathrm{n}} \mathrm{H}_{2 \mathrm{n}}+\mathrm{nH}_{2} \mathrm{O} \quad$ (cobalt catalyzed)

Alcohol production: $2 \mathrm{nH}_{2}+\mathrm{nCO} \rightarrow \mathrm{C}_{\mathrm{n}} \mathrm{H}_{2 \mathrm{n}+1} \mathrm{OH}+(\mathrm{n}-1) \mathrm{H}_{2} \mathrm{O} \quad$ (cobalt or carbon nitride catalyzed)

For example, methane can be produced by reaction (15) as such: $3 \mathrm{H}_{2}+\mathrm{CO} \rightarrow \mathrm{CH}_{4}+\mathrm{H}_{2} \mathrm{O}$ (cobalt catalyzed)

But more simply, methane can be formed through the long-known Sabatier Process: $4 \mathrm{H}_{2}+\mathrm{CO}_{2} \rightarrow \mathrm{CH}_{4}+\mathrm{H}_{2} \mathrm{O}$

The Sabatier Process is strongly exothermic and is spurred by reaction at $480-680 \mathrm{~K}$ over ruthenium or nickel catalysts. On Mars, the water reaction product would be subjected to electrolytic formation of hydrogen and recycled into the process, or otherwise utilized.

Once the basic hydrocarbons are produced, they must be distilled because yields are impure. Further chemistry is required to produce branched-chain hydrocarbons and complex organics. Any number of polymers can be generated. The basics of the Martian petrochemical industry will similar to that on Earth, except we will not have the advantage

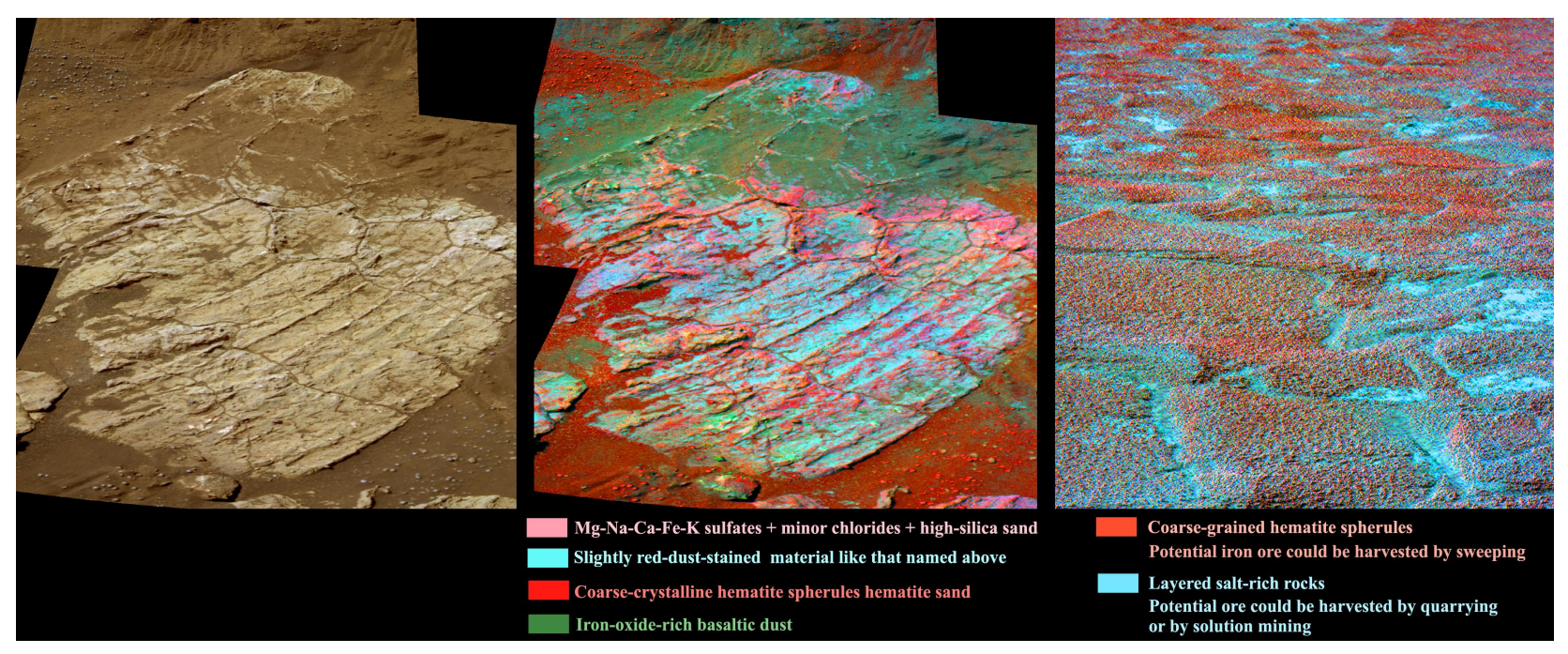

Fig. 3. NASA's Opportunity rover explored potential Mars resources. Left: Light-toned mud-cracked rock $(\sim 0.6 \mathrm{~m}$ or 2 feet across) is composed of magnesium-calcium-iron-sodium-potassium-rich sulfates and minor chlorides and silica-rich material. Middle: extreme enhancement shows compositional details. Right: Color-enhanced panorama shows a thin layer of hematite granules (potential iron ore) overlying salt-rich rocks (another potential rich resource). These deposits were discovered by orbit-based remote sensing (Christiansen et al. 2001, Hynek et al. 2002) but were characterized and explored from the surface (Squyres et al. 2004) in the detail needed to exploit the deposits. Any mining here would likely entail sweeping or raking of the hematite spherules and quarrying of the bedded salt deposits. The richest hematite deposits cover an area of about $10,000 \mathrm{~km}^{2}$, but less spectacular enrichments extend a further $200,000 \mathrm{~km}^{2}$ in this region of Meridiani Planum. One square kilometer, if swept completely of its partial monolayer of 2-mm granules, would yield about 3000 metric tons of iron once the iron oxide is reduced to elemental iron. The sulfate deposits (from which the hematite is eroding and accumulating on the surface), however, are tens and possibly hundreds of meters thick. A quarry $10 \mathrm{~m}$ deep and $100 \mathrm{~m}$ radius could supply a Mars settlement of 100 people for 90 years with $20 \mathrm{~kg} / \mathrm{person}$ per day of water (for consumption of water, oxygen for respiration, water for agriculture, hydrogen and oxygen and water for industrial uses; Kargel 2004) and other materials needed to survive and grow a human presence. The iron, ceramics, hydrocarbon polymers, photovoltaics, fertilizers, and other materials manufactured from these resources and Martian air (see main text for details) would be sufficient to build a habitat, the greenhouses, photovoltaic arrays, and other facilities sufficient to expand a small initial outpost to a settlement of 100 people and sustain it for 90 years. 
of starting with a complex hydrocarbon solution (petroleum), and the end products will place less emphasize on the low-mass portable alkanes that so dominate Earth's energy and transportation industry. Carbonaceous asteroids, on the other hand, provide hydrocarbon and organic mixtures seemingly designed for a petrochemical industry, whereas the Moon is always going to be a challenge, unless south polar carbon volatiles can be found. On either the Moon or Mars, hydrocarbons and organics could potentially be imported from carbonaceous asteroids as an alternative to manufacturing them from inorganic carbon and other feedstocks. Finally, for Mars there is the possibility that a vast amount of methane and other hydrocarbons, perhaps even petroleum-like deposits, exist and is the source of atmospheric methane discovered recently; however, considerable geologic exploration would be needed to identify the source. For further concepts regarding Martian resources and industrialization/settlement of Mars, the reader is referred to Kargel (2004).

In many respects Mars is geologically more like Earth than any other object, and in global composition it is a contender with Venus for having the most Earthlike composition. However, Mars' colder environment, lack of an extant liquid water ocean, smaller size and lack of plate tectonics, and lack of or low intensity of biological activity have led to a very different geological and geochemical/mineralogical montage than Earth has. For instance, more extensive cold trapping of complex assemblages of volatiles and salts in the crust has occurred on Mars due to its low surface temperatures. Differences in conditions of core formation and differences in the thermal states of the planetary cores and mantles, and differences in recycling of surface volatiles into the mantles have led to markedly divergent distributions and abundances of some elements and minerals on Earth and Mars.

Effective exploitation of Martian resources will require a thorough understanding of the differences as well as similarities of Earth and Mars as well as special schemes of resource utilization based on the unique requirements for survival and growth of an early industrial economy on Mars. What is needed to build a Mars civilization are abundant, widespread Martian rocks, ubiquitous air, and water derivable from ice or hydrated minerals; plus lots of energy, which can be generated by solar photovoltaic farms or nuclear plants. A thorough geological reconnaissance of mineral and volatile resources on Mars is needed to support future human exploration and settlement. This should be conducted by a concerted program of intelligent robotic sensor deployment on, beneath, and above the Martian surface (Fink et al., 2005, 2006a, 2007). A unique opportunity for Mars (Kargel 2004) that is fast being lost on Earth (Strom 2007, IPCC 2007) is the potential for an intelligent, planned economy that may avert increasing global planetary ravages, which the haphazard advance of civilizations on Earth have imposed here.

\section{SUSTAINABILITY AND COLLECTIVE SECURITY SHOULD BE OUR STARTING PREMISES}

If there was ever a reason for international cooperation, it is to instill collective security and confidence in space development and eschew fleeting imposition of security from one side or another in what could only become a fruitless and dead-ended space tussle. Star Trek and Star Wars makes great entertainment, but it will not likely take America or Europe or the Chinese or anybody to the stars; it could doom us to a Stone Age future on Earth. Collective security rooted in assurances that investments made are investments sustained short of troublesome dealings from Cosmic Nature or technological failings. However the collective security is achieved, it must be achieved, or all the awe-inspiring engineering in the Universe will not take us where we intend.

Our current economic trajectory on Earth is unsustainable and should be remedied soon if we are to maintain the economic viability and resource base needed to expand our presence through the Cosmos and to maintain civilization on Earth; our expansion to the Moon, Mars, or elsewhere ought to be rooted from the start in a concept of sustainability, which incorporates from the start a strategy to get off the exponential curve of population growth and resource depletion. The challenge to set off with the right approach, because the impression one may get from some sources (e.g., Lewis 1997) is of limitless resources of hitherto unexploited worlds just waiting to bring riches and well being to humans on Earth; however, translating those resources into improved quality of life on Earth will be a huge challenge and will be done in comparatively small measured steps, at least in the coming century. Space resources likely will have the greatest benefit in spurring space civilization, with Earth remaining the principle inhabited world until we reach the stars. Space resources, however, will prove crucial in making that reach to the stars in the long term, and in increasing low-Earth orbit development for betterment of life on Earth in the nearer term. 
Control of our ability to remake or destroy worlds ought to become a topic of international discussion and agreement. With international competition for access to space resources and lack of any regulatory order, runaway use of intelligent robotic systems, and unwise implementation with technical success may permanently devastate our planet and others. It makes no sense to rove from one planet to another in a wave of resource use and depletion, like interplanetary locusts moving from one field to another. Though Lewis (1997) may have been just underscoring the true vastness of potential future asteroid resources, Lewis' (1997) estimation that the Solar System can support $10^{16}$ people (Lewis 1997) does conjure an uncontained plague of locusts, or perhaps the most virulent cancer ever! Particularly when robotic systems are fully exploited, concepts of sustainability are vital, as the only thing more prone to cancerous runaway than humans would be reproducing armies of robots made in Man's image. The ultimate intelligence test for humans may be in the capacity to "just say no" at the appropriate time and circumstances. If we do not tackle the sustainability issue for planet Earth (Strom 2007, IPCC 2007), there is little hope that we will do so for other planets, and hence, little hope that civilization can maintain its economic capacity for the long reach to the stars.

Enthusiasm for planetary exploration, technology development, and the settlement of outer space must be balanced to benefit society, which for the most part will reside on Earth for a very long time to come. Our expansion to the Moon, Mars, or elsewhere should be rooted in sustainability, which incorporates from the start a strategy to get off the exponential curve of population growth, per-capita consumption, and resource depletion. We can calculate the impact on Martian resource supplies and the environment of a relatively small settlement of 100 people, and the impact is fairly small, even after centuries, so long as the inhabitants retain efficient Spartan ways. We can envisage and probably could build cities with millions of people on Mars and have each of them drive their personal 3 tons of steel for their personal commute across the crater; the question would be why? We may be unable to answer this question now, as the merit of a vast expansion of civilization beyond Earth will be settled by the people of the future. It does not seem wise, however, to start out envisioning an unsustainable endless exponential growth of humans or our robots and urban trappings on Mars, on Earth, or anywhere. One thing is sure: such exponential growth as we have had on Earth since the advent of modern science 400 years ago will have an end if the domain of our sustenance is the solid bodies in our Solar System.

Space does indeed offer new beginnings, but these should be good and strong new beginnings, not the beginning of a repeat of the past, which served the past arguably well but threatens the future. More complete use should be made now of nonrenewable resources on Earth and when we move outward from Earth. Perhaps the greatest benefit of space development and settlement in the 21st Century will issue from the wisdom and technology gained through Spartan ways of living and prospering in outer space. Earth will remain the lap of luxury relative to life in outer space for quite some time to come. Nevertheless, we here on Earth will learn more sustainable ways, such as manufacturing houses and working places and appliances and other things that endure, transportation systems that move people more efficiently, ways of building cities that require less movement and enable more work and more play and require less maintenance of peoples' bodies and of our urban structures, need less energy for heating and cooling, and entail less tearing down and rebuilding back up. Our civilization in space will be forced to develop technologies and habits that increase the efficiency of utilization of raw materials, which can translate to an improved economy on Earth. Getting control of the exponential curve of resource consumption and depletion is paramount no matter what planet is the one being civilized.

We have every expectation that a Mars economy or integrated space economy will be a market-driven capitalmotivated economy, but the rules of market capitalism must change to punish waste and reward true globalistically defined efficiency - on Earth as well as Mars. Space settlement will teach our leaders and the masses of consumers that a higher quality of life can be constructed if we consume less of the senseless stuff that fills our lives and garages. Success in doing things in outer space can instill in us a new way of growing our civilization here on Earth through the recognition that economic vitality and the real essence of life-enhancing gross world product does not equate to tonnage of raw materials consumed and depleted. A globalistically defined efficiency-motivated market economy can function better and make nations more prosperous than our current waste-rewarding market economy; this concept carries interplanetary wisdom that will work for Earth as much as for Mars and will enhance individual well being. The rules of market capitalism should be modified for space and for Earth so as to achieve this goal; the consequences of failure to do so would be the failure of civilization on Earth and in space. 


\section{CONCLUSIONS}

The visions laid out by O'Neill et al. (1976), Zubrin and Wagner (1996), and others is compelling, but the hoped-for success of Mars settlement or asteroid mining or lunar development could lead quickly to self-limiting or selfdefeating progress that renders the enterprise closed-ended; or worse, to the devastation of the worlds we wish to serve as stepping stones to the stars (Kargel 2004). The most strategically well placed near Earth asteroids and valuable water resources at the lunar poles may be depleted faster than anybody now thinks likely; or international competition for those materials and the lunar high ground may render none of us able to achieve anything lasting beyond Earth. The recent cycle of anti-satellite tests highlights possibilities that even low Earth orbit could be rendered useless for everybody by competing national aspirations to control space.

We would serve our future in space well by figuring out in advance why we will go to Mars, why we would mine lunar polar ice, or why we would extract platinum from asteroids. The future, of course, will take care of itself and ultimately will pay little heed to today's wisdom. However, if we take serious missteps right at the beginning, a calamitous dead end may be achieved sooner than anybody would wish, and we might not have a chance to do it again with greater wisdom. An unrestrained and ill-conceived international competition for valuable real estate, such as the lunar South Pole, could very well deny all contenders the chance to develop lunar resources. Hidden purposes in driving lunar and planetary exploration could well snowball into suddenly conflicting projects and snatch defeat for everybody from the jaws of victory.

The greatest promise of space settlement may be achieved with a view toward development of an integrated economy for the inner Solar System, where the best attributes of several objects may be exploited. The first thing to do is to get the justification for planetary resource exploration and development right, not basing it on overblown promises and unachievable or hidden goals, but by basing it solidly on something that resonates with the tens of thousands people who will lend their professional careers to the goal of settling Mars or developing the Moon's South Pole or mining an asteroid, and the millions more who will bear the tax burden to make that happen. The justification necessarily will involve development of a sound economy, because without an economy there is no means to sustain the activity. An economy must rest on natural resources, as well as other attributes of the Solar System's places (such as location). Effective use of the natural resources and construction of a Solar System economy first requires a survey of what's out there. This can be done economically mainly robotically.

\section{REFERENCES}

1. Baker, V. R., et al., 1993, Water resources and hydrology of Mars, in: Resources of Near-Earth Space, J.S. Lewis, (Ed.), Univ. Arizona Press, Tucson, p. 765.

2. Christensen, P. R., Morris, R. V., Lane, M. D., Bandfield, J. L., and Malin, M. C. (2001) Global mapping of Martian hematite mineral deposits: Remnants of water-driven processes on early Mars. Journal of Geophysical Research, v. 106 (E10), p. 23,873-23,885.

3. Fink, W., et al., 2005, Next-Generation Robotic Planetary Reconnaissance Missions: A Paradigm Shift; Planetary and Space Science, 53, 1419-1426.

4. Fink, W., et al., 2006a, Autonomous Tier-Scalable Reconnaissance Missions For Remote Planetary Exploration; Proceedings of the 4th International Planetary Probe Workshop 2006, Pasadena.

5. Fink, W., et al., 2007, Tier-Scalable Reconnaissance Missions For The Autonomous Exploration Of Planetary Bodies; IEEE Aerospace Conference Proceedings, Big Sky, Montana.

6. Fink, W., et al., 2008, Automated Global Feature Analyzer (AGFA) - A Driver for Tier-Scalable Reconnaissance, IEEE Aerospace Conference Proceedings, Big Sky, Montana.

7. Fink, W., 2006b, Generic Prioritization Framework for Target Selection and Instrument Usage for Reconnaissance Mission Autonomy, Proceedings of IEEE World Congress on Computational Intelligence (WCCI) 2006, Vancouver, Canada, 11116-11119.

8. Furfaro, R. et al., 2008, The search for life beyond Earth using fuzzy expert systems, Planetary Space Sci., in press.

9. Glaser, P., F.P. Davidson, and K. Csigi, 1998, Solar Power Satellites: A Space Energy System for Earth, John Wiley \& Sons. 
10. Hynek, B. M., Arvidson, R. E., and Phillips, R. J. (2002) Geologic setting and origin of Terra Meridiani hematite deposit on Mars. Journal of Geophysical Research, v. 107, no. E10, 5088, doi: 1029/2002001891.

11. IPCC, 2007, Climate Change 2007 - The Physical Science Basis, Contributions of Working Group 1 to the Fourth Assessment Report of the IPCC, ISBN 9780521 70596-7 Paperback.

12. Kargel, J.S., 1994, Metalliferous asteroids as potential sources of precious metals J. Geophys. Res. v. 99, p. 21,129 .

13. Kargel, J. S., 1996, Market value of asteroidal precious metals in an age of diminishing terrestrial resources, in Engineering, Construction, and Operations in Space V, Proc. 5th Int'l Conf. on Space '96 (ed. S. W. Johnson).

14. Kargel, J. S., 1997, Semiconductor and precious-metal resources of metallic asteroids, Princeton Conf. on Space Manufacturing, Space Studies Inst.

15. Kargel, J.S., 2004, Mars: A Warmer, Wetter Planet, Praxis-Springer, 557 pages.

16. Lewis, J.S., (Ed.), 1993, Resources of Near-Earth Space, Univ. Arizona Press, Tucson.

17. Lewis, J.S., 1997, Mining the Sky: Untold Riches from the Asteroids, Comets, and Planets, Helix Books/Perseus Books, Paperback, 274 pages, ISBN No. 0-201-32819-4.

18. Miyamoto, H., and 14 others, 2007, Regolith Migration and Sorting on Asteroid Itokawa, Science, DOI: $10.1126 /$ science. 1134390 .

19. O'Neill, G.K., 1976, The High Frontier, Bantam Books/SSI Press, ISBN: 0-9622379-0-6.

20. Schmitt, H.H., 1990, Apollo 17 Orange Soil : Interpretation of Geologic Setting, Workshop on Lunar Volcanic Glasses: Scientific and Resource Potential. A Lunar and Planetary Institute Workshop, sponsored by LPI and the Lunar and Planetary Sample Team, held October 10-11, 1989, at the Lunar and Planetary Institute, in Houston, Texas. Edited by John W. Delano and Grant H. Heiken. LPI Technical Report 90-02, published by Lunar and Planetary Institute, 3303 NASA Road 1, Houston, TX 77058, 1990, p.56.

21. Squyres, S.W. and 49 others, 2004, The Opportunity Rover's Athena Science Investigation at Meridiani Planum, Mars, Science 306, 1698-1703.

22. Strom, R., 2007, Hot House, Praxis Publishing, 302 pages.

23. Zubrin, R., and R. Wagner, 1996, The Case for Mars: The Plan to Settle the Red Planet and Why we Must, ISBN-10 0684827573 .

24. Zubrin, R., B. Frankie, and T. Kito, 1997, Mars in situ resource utilization based on reverse water gas shift: Experiments and mission 